\title{
Prosthodontic Management of Brothers affected from Anhydrotic Ectodermal Dysplasia
}

\author{
${ }^{1}$ Rajiv Kumar Gupta, ${ }^{2}$ Thallam Veer Padmanabhan, ${ }^{3}$ Bijoy Thomas \\ ${ }^{1}$ Senior Resident, Department of Prosthodontics, Maulana Azad Institute of Dental Sciences, New Delhi, India \\ ${ }^{2}$ Professor and Head, Department of Prosthodontics and Implantology, Sri Ramachandra Dental College, Tamil Nadu, India \\ ${ }^{3}$ Postgraduate Student, Department of Prosthodontics and Implantology, Sri Ramachandra Dental College, Tamil Nadu, India
}

Correspondence: Rajiv Kumar Gupta, Senior Resident, Department of Prosthodontics, Maulana Azad Institute of Dental Sciences New Delhi, India, e-mail: dent.rajiv@gmail.com

\section{ABSTRACT}

Anhydrotic ectodermal dysplasia is a rare congenital disease that can affect several ectodermal structures, such as hair, teeth, skin, nails, sweat and sebaceous glands. It is commonly a difficult condition to manage with prosthodontics because of the typical oral deficiencies and also patients are quite young when they are evaluated for treatment. This clinical report describes the management of two brothers affected by ectodermal dysplasia, prosthodontically. It is important that these patients should get dental treatment at an early stage for physiologic and psychosocial reasons. Dental treatment can vary depending upon the severity of the disease. This case report describes the use of removable partial dentures to replace congenitally missing teeth, and composite resin material to restore the conical maxillary central incisors to achieve a favorable esthetic result. This approach rehabilitates patients without sacrificing healthy dental tissues.

Keywords: Anhydrotic ectodermal dysplasia, Christ-Siemens-Touraine syndrome, Prosthodontic management, $\mathrm{X}$-linked recessive disorder.

\section{INTRODUCTION}

The ectodermal dysplasia (EDs) comprises a large, heterogeneous group of inherited disorders that are defined by primary defects in the development of two or more tissues derived from embryonic ectoderm. The tissues primarily involved are the skin, hair, nails, eccrine glands and teeth. ${ }^{1,2}$ Freire-Maia-Pinheiro have described 154 patterns of ectodermal dysplasias, divided them into 11 subgroups and then classified them according to the involved structures (the hair, the teeth, some or all of the sweat glands). ${ }^{3}$

The most frequent form is the Christ-Siemens-Touraine syndrome, a recessive autosomal disorder characterized by an anomalous development of the ectodermal structures. Depending upon the severity of the clinical manifestations, Christ-Siemens-Touraine syndrome can be classified as hypohydrotic ectodermal dysplasia, or as anhydrotic ectodermal dysplasia. ${ }^{4}$ Three clinical signs are necessary to establish a diagnosis of Christ-Siemens-Touraine syndrome, and they are hypotrichosis (lack of hair), absence or reduction in number of teeth and absence or diminution of sweat glands. ${ }^{5}$

The frequency of the different EDs in a given population is highly variable. Collectively, the prevalence of ED is estimated at seven cases per 10,000 births. ${ }^{1,6}$ The EDs have been reported most often in whites, but they have also been reported in persons of other races. ${ }^{1} \mathrm{X}$-linked recessive ED has full expression only in males due to the presence of only chromosome $\mathrm{X}$ while women carrier show little or no signs of the condition. Although the complete syndrome has been reported in women. ${ }^{1,7,8}$
X-linked anhydrotic ectodermal dysplasia is caused by mutations in ectodermal dysplasias anhydrotic (EDA), which is located in position q12-q13 of the X-chromosome. ${ }^{9}$ It encodes the ectodysplasin protein, a soluble ligand that activates the NF-kappa B and JNK/c-fos/c-jun signaling pathways. Ectodysplasin is important in promoting cell survival, growth and differentiation. ${ }^{1}$ Another mutation (A1270G) has also been revealed to be responsible for Tyr343cys substitution in patients with anhydrotic ectodermal dysplasia. ${ }^{10}$

The typical facies of ED, which is often not recognized until infancy is characterized by frontal bossing, sunken cheeks, saddle nose, thick everted lips, wrinkled and hyperpigmented periorbital skin. Dental manifestations include conical or pegged teeth, hypodontia or complete anodontia, and delayed eruption of permanent teeth. ${ }^{1}$ The average number of missing permanent teeth is reported as 23.7. ${ }^{11}$ The maxillary central incisors, maxillary first molars, mandibular first molars and maxillary canines are the teeth most often present. ${ }^{12,13}$ The maxillary central incisors and the maxillary and mandibular canines are usually conical in shape. The alveolar process fails to develop at edentulous sites and may be poorly developed even at dentate sites. ${ }^{14-16}$

Dental management of ED patients traditionally focuses on provision of a series of complete or removable partial dentures during the growing years ${ }^{17}$ and definitive rehabilitation following completion of jaw growth. ${ }^{13,18}$ The patient's age, the pattern of dysplasia, number and morphology of present teeth and the morphology of alveolar ridges influence the dental treatment. The intent of this clinical report is to highlight the 
conservative approach of prosthetic management of the patients with anhydrotic ectodermal dysplasia.

\section{CASE REPORT}

Two brothers, 10 and 12 years old, reported with the chief complaint of lack of teeth and inability to chew properly, to the Department of Prosthodontics and Implantology, Sri Ramachandra Dental College, Chennai, India.

On examination, they exhibited the classical features of ED: hypodontia, anhydrosis, hypotrichosis, prominent forehead, decreased lower anterior facial height, flat mandibular plane, saddle nose, thin upper lip, everted lower lip, prominent chin and a resultant concave facial profile (Figs 1 and 3).

The intraoral examination showed the presence of four teeth: Two conical maxillary central incisors and two maxillary left molars in younger brother (Figs 2 and 5) and two teeth: one left and one right maxillary molar in elder brother (Figs 4 and 7). Mandibular arches were completely edentulous in both cases. Both patients exhibited the loss of vertical dimension, the absence of alveolar processes and an anomalous development of alveolar ridges (Figs 6 and 8). OPGs revealed aplasia of alveolar bone and absence of other teeth buds for

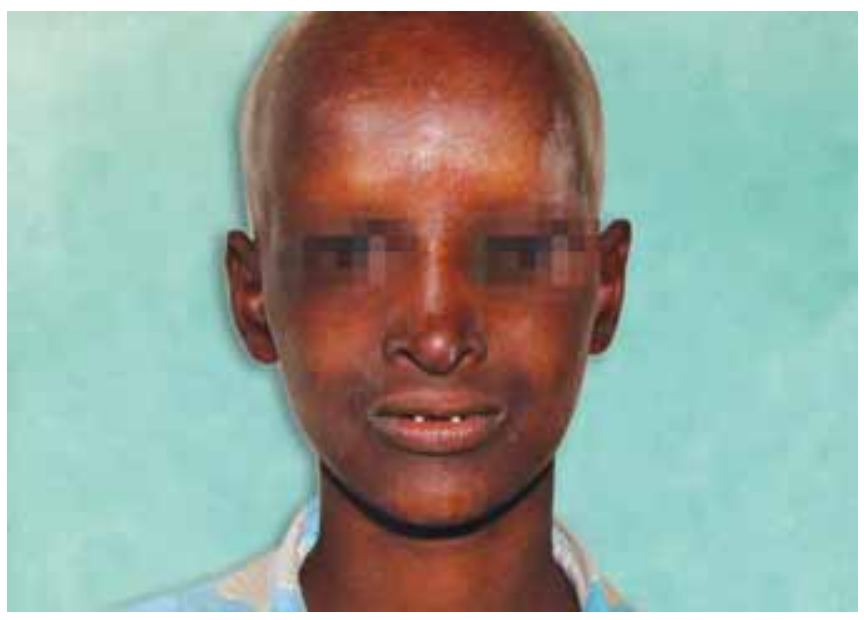

Fig. 1: Patient A-frontal view

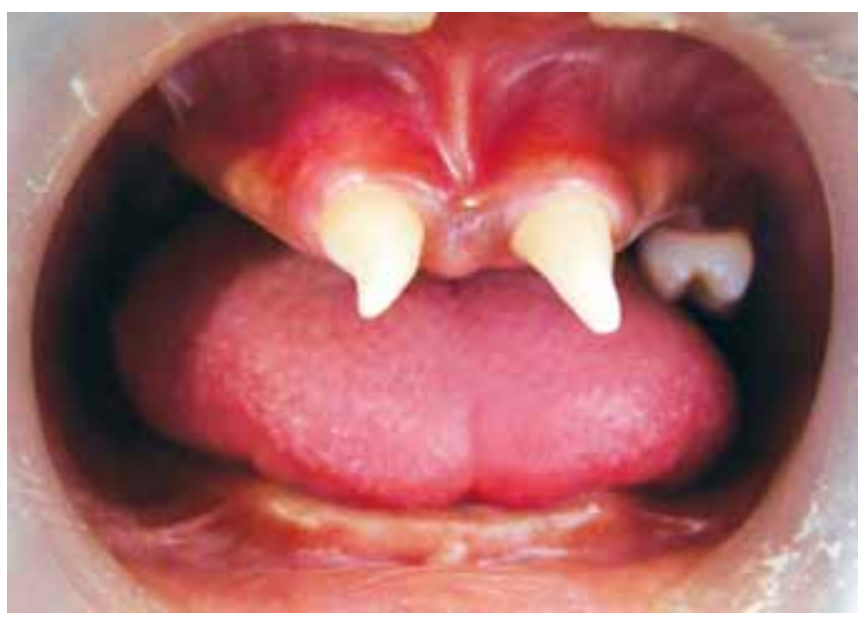

Fig. 2: Patient A-intraoral view both cases. Maxillary incisors showed open apices whereas all other teeth had their root formation completed (Figd 9 and 10).

Considering the age of the patients and the poor amount of alveolar bone present, treatment option considered for younger child included constructing removable partial denture for maxillary arch after reshaping the conical maxillary central incisors with composite (Fig. 11) and complete denture for mandibular arch (Fig. 12). For elder child, treatment included fabrication of removal partial denture for maxillary arch and complete denture for mandibular arch (Fig. 13). This therapeutic approach provided for the psychological and social comfort of our young patients. It was considered that osseointegrated implants would play a significant role in the definitive restoration of the occlusion. However, as the young patients were growing, it was decided to defer the definitive restorative phase, including the placement of implants, until after the completion of jaw growth and eruption of other permanent teeth, if there, and closure of space between maxillary central incisors for younger patient using orthodontics after completion of root formation.

Periodic recalls of young ED patients are also important because prosthesis modification or replacement will be needed as a result of continuing growth and development. ${ }^{17,19,20}$

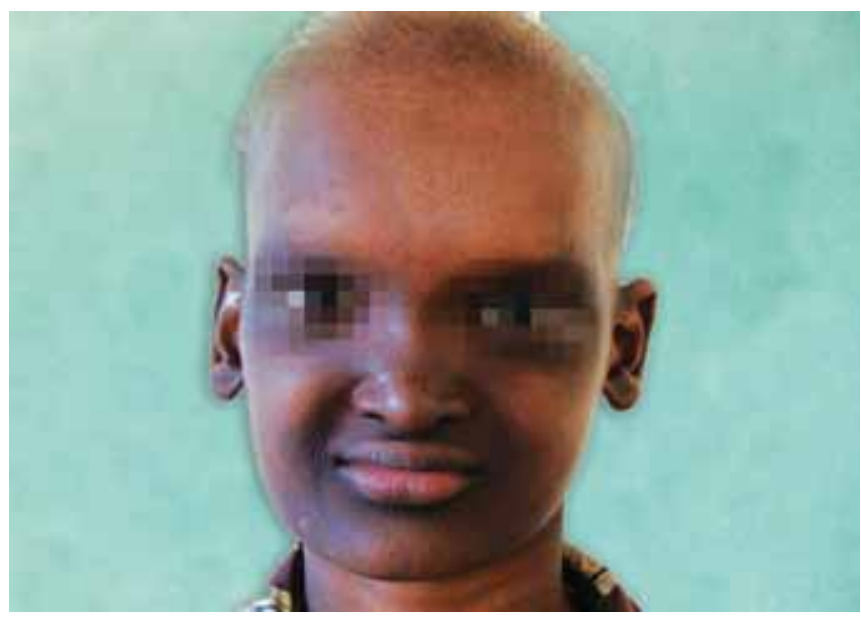

Fig. 3: Patient B-frontal view

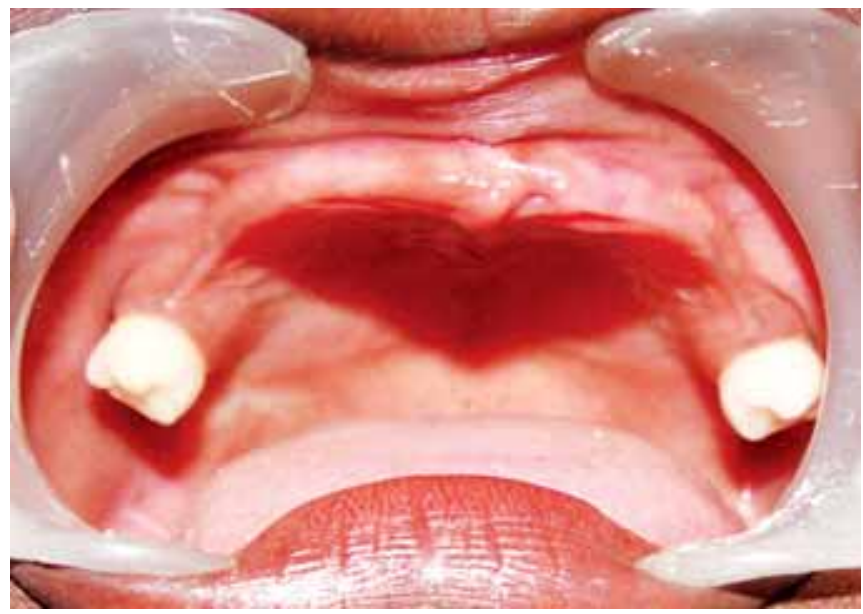

Fig. 4: Patient B-intraoral view 


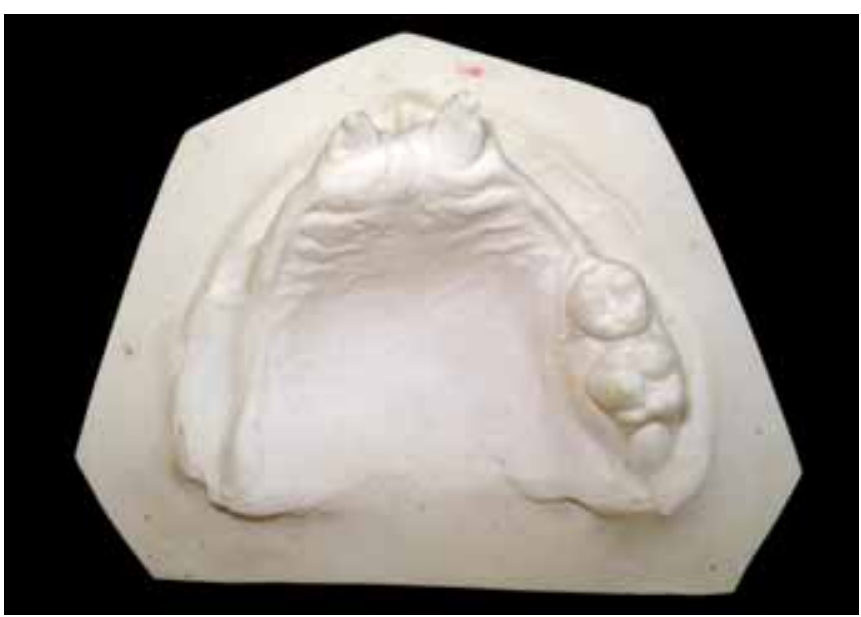

Fig. 5: Maxillary diagnostic cast of patient $A$

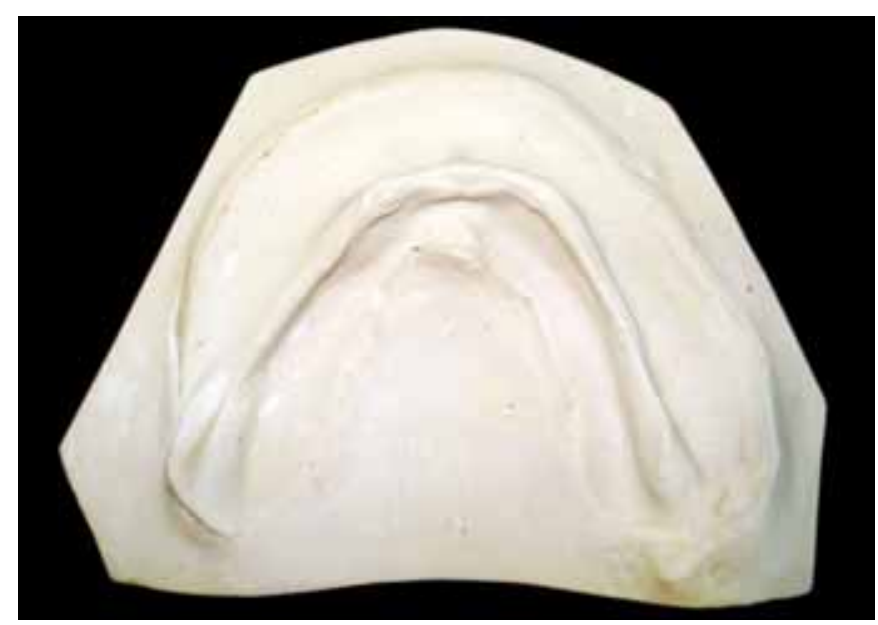

Fig. 6: Mandibular diagnostic cast of patient A

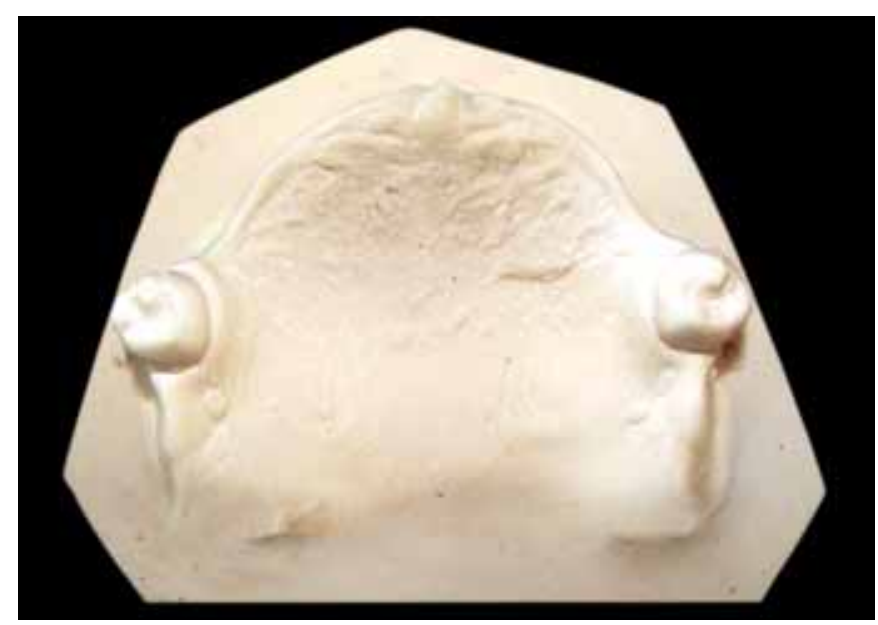

Fig. 7: Maxillary diagnostic cast of patient B

In addition to adjustments related to fit, the occlusion of a prosthesis must be monitored for changes because of jaw growth. ${ }^{20}$ For this, recall appointments were scheduled for 24 hours, 3 days, 2 weeks, 4 weeks, every 3rd month for the first year and every 4 th month till completion of growth. Written oral hygiene instructions were given and explained to the

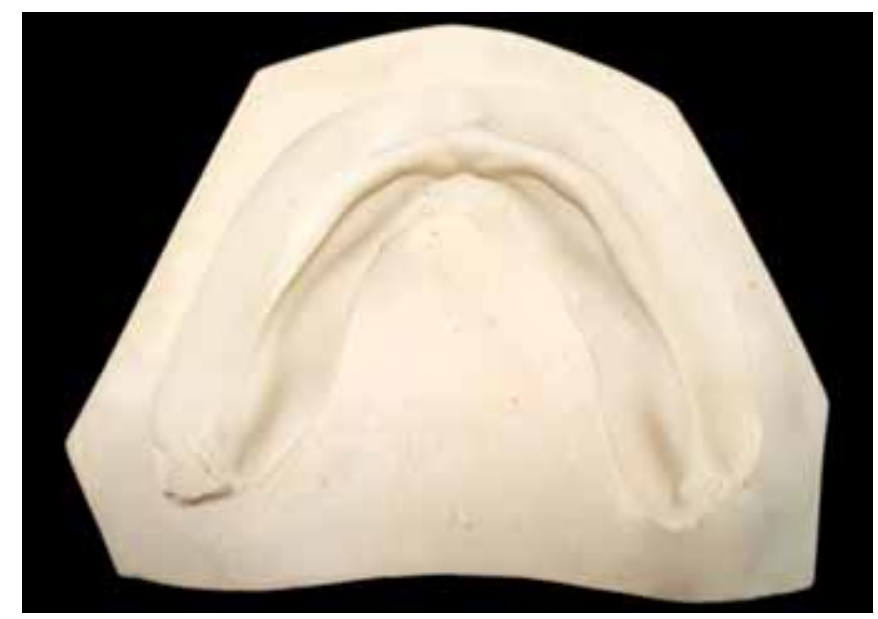

Fig. 8: Mandibular diagnostic cast of patient B

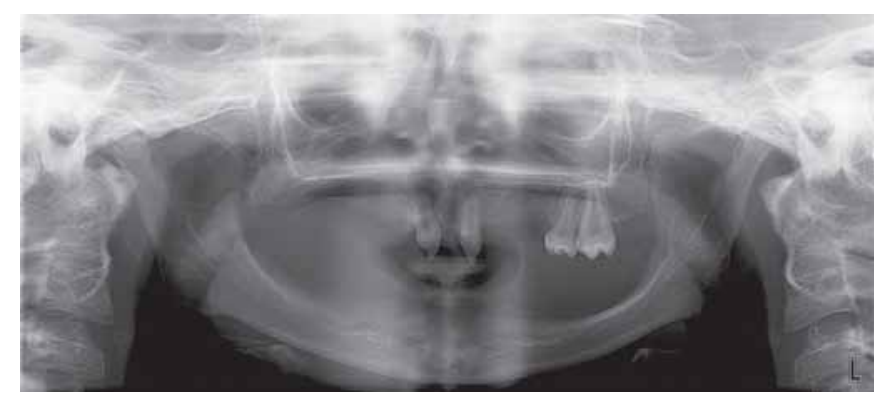

Fig. 9: Panoramic radiograph of patient $A$

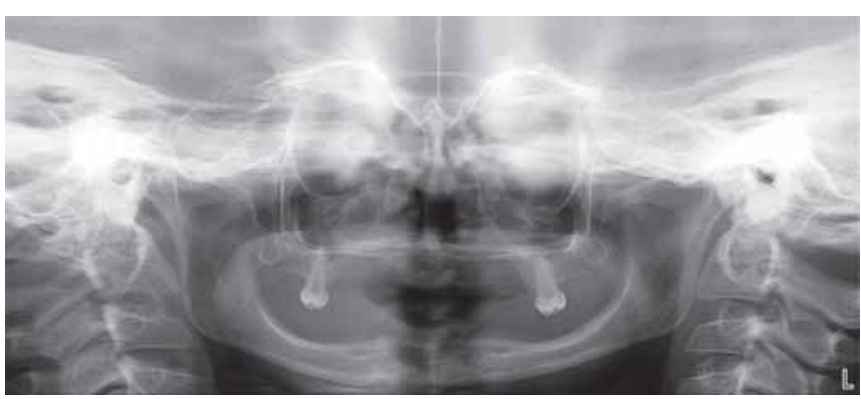

Fig. 10: Panoramic radiograph of patient $B$

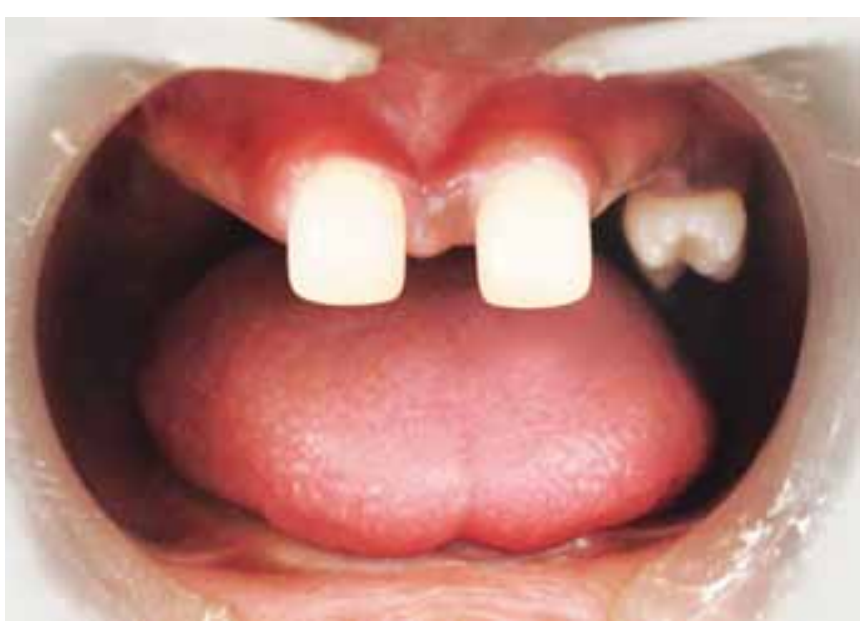

Fig. 11: Maxillary anterior teeth restored with composite resin for patient $A$ 


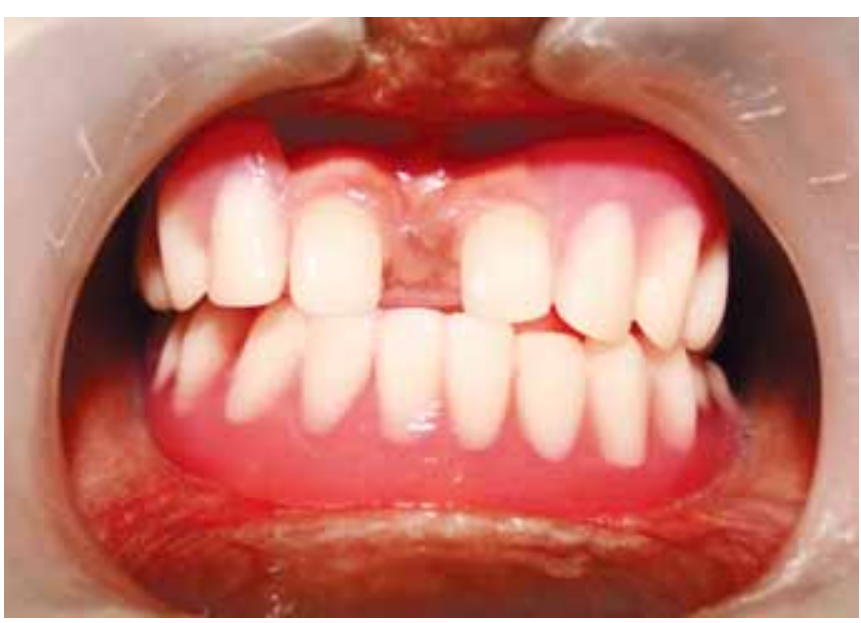

Fig. 12: Removable dentures in mouth for patient $A$

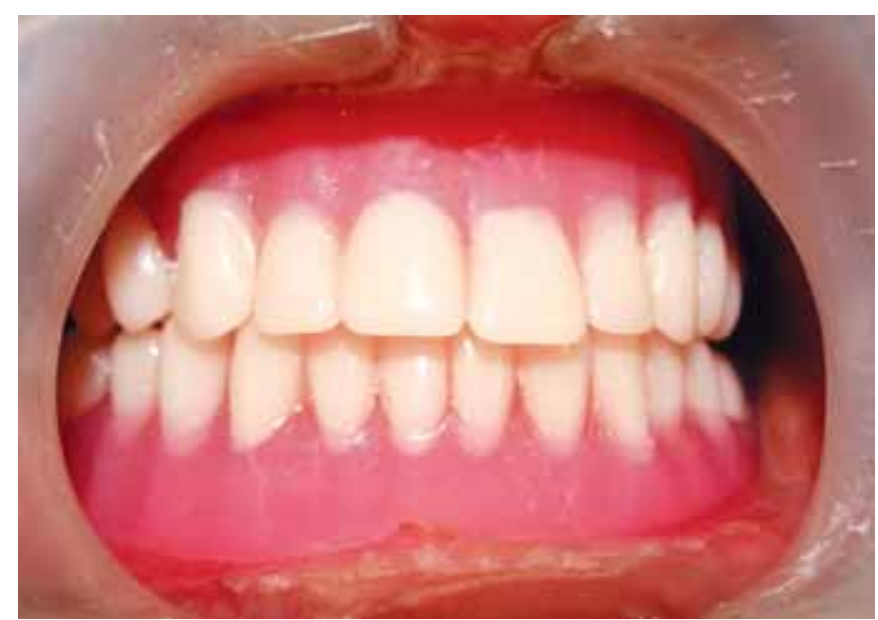

Fig. 13: Removable dentures in mouth for patient B

patients and their parents also. Patients were satisfied with their improved appearance and masticatory ability. Parents were explained that these removable partial and complete dentures will be worn until the completion of facial growth, at which time a second phase of definitive treatment to prepare for dental implant-supported restorations will be initiated.

\section{DISCUSSION AND SUMMARY}

Nowak stated that "treating the pediatric patient with ED requires the clinician to be knowledgeable in growth and development, behavioral management, techniques in the fabrication of a prosthesis, the modification of existing teeth utilizing composite resins, the ability to motivate the patient and parent in the use of the prosthesis, and the long-term followup for the modification and/or replacement of the prosthesis. ${ }^{19}$

Our approach for the management of these patients was mainly guided by their age and the necessity to ensure conservation of their present dentition. The aim of our treatment was to restore the functional needs of the patients. Improvement of the patient's facial esthetics and masticatory function were important in allowing them to integrate with others of their age, to prevent any psychological repercussions and to maintain their self-esteem.
Development of new techniques and the availability of innovative materials facilitate the oral rehabilitation of a patient with ED. Adhesive resin materials can be used for the conservative and esthetic restoration of the peg-shaped teeth. ${ }^{4}$ Recently, direct composite restorations have become the more desirable method of restoring normal morphology to hypoplastic teeth commonly found in ED patients. ${ }^{19,21}$

Fixed prosthodontic treatment is seldom used exclusively in the treatment of ED, primarily because many afflicted individuals have a minimal number of teeth. In addition, ED patients are often quite young when they are first treated, and FPDs with rigid connector should be avoided in young, actively growing patients. This is because rigid FPDs could interfere with jaw growth, especially if the prosthesis crosses the midline. $^{21}$

The literature indicates that endosteal implants are being used more widely in the prosthodontic management of ED. A 1989 Consensus Conference on Implantology concluded that implants should not be used until maximum jaw growth has occurred, which was reported as up to 15 years of age. ${ }^{21}$ Implants placed after age 15 years for girls and 18 years for boys provided the most predictable prognosis. ${ }^{22}$ The possible consequences of early implant placement include implant submergence because of jaw growth, implant exposure because of bone resorption associated with jaw growth, implant movement because of jaw growth, and limitation of jaw growth if the implants are connected by a rigid prosthesis that crosses the midline. ${ }^{21,22}$

Removable prosthodontics is the most frequently used treatment modality for dental management of ED. Although complete dentures are an acceptable form of treatment, overdentures or RPDs supported by natural teeth are desirable for preservation of alveolar bone. ${ }^{21}$ Individuals with ED are routinely managed by a series of dentures during the growing years and definitive habilitation following the completion of jaw growth.

\section{REFERENCES}

1. eMedicine: Ectodermal Dysplasia: Article by Kara N Shah. www.emedicine.com/derm/topic114.htm-100K

2. Dhanrajani PJ, Jiffiy AO. Management of ectodermal dysplasia: A literature review. Dent Update 1998;25:730-75.

3. Pinheiro M, Freire-Maia N. Ectodermal dysplasias: A clinical classification and casual review. Am J Med Genet 1994; 53: 153-62.

4. Lo Muzio L, Bucci P, Carile F, Riccitiello F, Scotti C, Coccia E, Rappelli G. Prosthetic rehabilitation of a child affected from anhydrotic ectodermal dysplasia: A case report. J Contemp Dent Pract 2005;3(6):120-26.

5. Gardel P, Mercier C, Molhant G. Christ-Siemens-Touraine syndrome: A new case. Rev Stomatol Chir Maxillofac 1984; 85:115-18.

6. Buyse ML. Birth defects encyclopedia. Cambridge: Blackwell Scientific Publication 1990:596-605.

7. Herer PD. Treatment of anhydrotic ectodermal dysplasia: A case Report. J Dent Child 1975;42:133-36. 
8. Ali G, Kumar M, Verma R, Khajuria V, Wadhwa MB. Anhydrotic ectodermal dysplasia (Christ-Seimens-Touraine syndrome): Case report with a review. Indian J Med Sci 2000; 54:541-44.

9. Hertz JM, Norgaard Hausen K, Juncker I. A novel missense mutation (402CàT) in exon 1 in the EDA gene in a family with X-linked hypohydrotic ectodermal dysplasia. Clin Gent 1998; 53:205-09.

10. Kobielak A, Kobielak K, Biedziak B. A novel mutation A1270G of the EDA 1 gene causing Tyr343Cys substitution in ectodysplasin-A in a family with anhydrotic ectodermal dysplasia. Acta Biochimica Polonica 2003;50:255-58.

11. Crawford PJ, Aldred MJ, Clarke A. Clinical and radiographic dental findings in X-linked hypohydrotic ectodermal dysplasia. J Med Genet 1991;28:181-85.

12. Nakata M, Koshiba H, Eto K, Nance WE. A genetic study of anodontia in X-linked hypohydrotic ectodermal dysplasia. Am J Hum Genet 1980;32:908-19.

13. Guckes AD, Roberts MW, McCarthy GR. Pattern of permanent teeth present in individuals with ectodermal dysplasia and severe hypodontia suggests treatment with dental implants. Pediatr Dent 1998;20:278-80.

14. Everet FG, Jump JB, Sutherland WF, Savara BS, Suher T. Anhydrotic ectodermal dysplasia with anodontia: A study of two families. J Am Dent Assoc 1952;44:173-86.
15. Soderholm AL, Kaitila I. Expression of X-linked hypohydrotic ectodermal dysplasia in six males and in their mothers. Clin Genet 1985;28:136-44.

16. Tape MW, Tye E. Ectodermal dysplasia: A literature review and a case report. Compend Contin Educ Dent 1995;16: 524-28.

17. Sarnat BG, Brodie AG, Kubacki WH. Fourteen years report of facial growth in case of complete anodontia with ectodermal dysplasia, AMA. Am J Dis Child 1953;86:162-69.

18. Davarpanah M, Moon JW, Yang LR, Celletti R, Martinez H. Dental implants in the oral rehabilitation of a teenager with hypohydrotic ectodermal dysplasia: Report of a case. Int J Oral Maxillofac Implants 1997;12:252-58.

19. Novak AJ. Dental treatment of patients with ectodermal dysplasia. Birth Defects 1988;24:243-52.

20. Nomura S, Hasegawa S, Noda T, Ishioka K. Longitudinal study of jaw growth and prosthetic management in a patient with the ectodermal dysplasia and anodontia. Int J Paediatr Dent 1993;3:29-38.

21. Pigno MA, Blackman RB, Cronin RJ Jr, Cavazos E. Prosthodontic management of ectodermal dysplasia: A review of literature. J Prosthet Dent 1996;76:541-45.

22. Cronin RJ Jr, Oesterle LJ, Ranly DM. Mandibular implants and the growing patients. Int J Oral Maxillofac Implants 1994;9: 55-62. 